\title{
VANTAGENS COMPETITIVAS ASSOCIADAS À ADOÇÃO DA RESPONSABILIDADE SOCIAL CORPORATIVA E À PARTICIPAÇÃO NO ÍNDICE DE SUSTENTABILIDADE EMPRESARIAL
}

Abel Casali Bianco

Especialista em Marketing Management, Instituto de Ensino e Pesquisa - INSPER, Brasil.

Analista de Inteligência de Mercado, Luxxotica

bianco.abelc@gmail.com

Tiago FonseCa AlbuQuerQue CavalCanti SigahI

Doutorando em Engenharia de Produção, Universidade de São Paulo - USP, Brasil.

tiagosigahi@usp.br

\section{PATRÍCIA SALTORATO}

Doutora em Engenharia de Produção, Universidade Federal de São Carlos - UFSCAR, Brasil.

Professor do Programa de Pós-Graduação em Engenharia da Produção do Campus-Sorocaba da Universidade Federal de São Carlos - PPGEPS/UFSCAR, Brasil.

patrisal@dep.ufscar.br

Marina Helena Pereira Vieira

Mestranda em Engenharia de Produção, Universidade Federal de São Carlos - UFSCAR, Brasil.

marinahelena3@hotmail.com

\section{Resumo}

O presente artigo explora os efeitos da adoção da Responsabilidade Social Corporativa (RSC) sobre o desempenho financeiro e a imagem das empresas frente aos stakeholders. Para tanto, foi realizada uma revisão integrativa combinando três instrumentos de coleta de dados: o exame dos relatórios publicados pelas empresas listadas no Índice de Sustentabilidade Empresarial da bolsa de valores B3; a pesquisa junto à imprensa de negócios e; a análise da literatura nacional e internacional. Embora o conceito ligado à RSC não possa ser considerado uma novidade, tampouco a discussão sobre sua relação com o desempenho das empresas, o debate está longe de ser concluído: alguns autores tratam a RSC como uma vantagem competitiva; outros afirmam não haver evidências suficientes para tal afirmação; e ainda há aqueles que defendam que os custos associados à RSC ainda são muito altos para as empresas e os que percebem simultaneamente vantagens e desvantagens em sua adoção.

Palavras-chave: Responsabilidade Social Corporativa, İndice de Sustentabilidade Empresarial, desempenho financeiro, imagem corporativa. 


\title{
COMPETITIVE ADVANTAGES ASSOCIATED WITH THE ADOPTION OF CORPORATE SOCIAL RESPONSIBILITY AND PARTICIPATION IN THE BUSINESS SUSTAINABILITY INDEX
}

\begin{abstract}
This article explores the adoption of practices related to Corporate Social Responsibility (CSR) effects on financial performance and image of companies against stakeholders. An integrative research was conducted combining three data collection procedures: research within the reports published by the companies listed in the Corporate Sustainability Index (B3 of the Brazilian stock exchange); research within the business press; and literature review (national and international). Although the concept of CSR cannot be considered new by itself, not even is the discussion about its relation to corporate performance, the debate is far from being concluded: some authors deal with CSR as a competitive advantage; others claim that there is not enough evidence to such assertion; and there are even those who argue that CSR costs are still too high for companies, and also those who see the existence of both advantages and disadvantages in adopting these practices.
\end{abstract}

Keywords: Corporate Social Responsibility, Corporate Sustainability Index, Financial Performance, Corporate Image.

\section{VENTAJAS COMPETITIVAS ASOCIADAS A LA ADOPCIÓN DE LA RESPONSABILIDAD SOCIAL CORPORATIVA Y A LA PARTICIPACIÓN EN EL İNDICE DE SUSTENTABILIDAD EMPRESARIAL (ISE)}

\begin{abstract}
Resumen
El presente artículo explora los efectos de la adopción de Responsabilidad Social Corporativa (RSC) sobre el desempeño financiero y la imagen de las empresas frente a los stakeholders. Para ello, se realizó una revisión integrativa combinando: examen de los informes publicados por las empresas listadas en el Índice de Sustentabilidad Empresarial (Bolsa de valores B3); investigación en la prensa de negocios; y análisis de la literatura. A pesar que el concepto vinculado a la RSC no puede ser considerado novedad, ni la discusión sobre su relación con el desempeño de las empresas, el debate está lejos de ser concluido: algunos autores tratan a la RSC como ventaja competitiva; otros afirman que no hay evidencia suficiente para tal afirmación; y todavía hay quienes defienden que los costos asociados a la RSC son altos para las empresas y los que a la vez perciben ventajas y desventajas en la adopción de RSC.

Palabras clave: Responsabilidad Social Corporativa, Índice de Sustentabilidad Empresarial, Desempeño Financiero, Imagen Corporativa.
\end{abstract}




\section{INTRODUÇÃO}

Em seu livro intitulado Social Responsibilities of the Businessman, Bowen (1953) deu início a uma discussão que hoje está presente não só na imprensa empresarial e no meio político, mas também na literatura acadêmica. No entanto, desde então, processou-se uma mudança na terminologia: 0 que era "responsabilidade social dos negócios" passou a ser conhecido como Responsabilidade Social Corporativa (RSC) (Garriga \& Melé, 2004).

Segundo Ferreira (2004), uma companhia só se diferencia no mercado, tornando-se candidata à atração de capital quando quatro princípios que norteiam as boas práticas de gestão transparecem junto aos investidores: transparência, equidade, prestação de contas e responsabilidade corporativa. Investidores, acionistas, consumidores (internos e externos) e demais stakeholders - todos assumem, em algum grau, o papel de fiscalizadores das práticas empresariais. Empresas que associam sua imagem ao meio ambiente sem exercer de fato ações de redução de impactos ambientais têm sido rotuladas como greenwashing, em outras palavras, tais organizações apresentam simultaneamente baixo desempenho ambiental e comunicação muito positiva deste desempenho (Antoniolli \& Dias, 2013).

A manutenção de uma boa imagem torna-se cada vez mais crucial para a consolidação organizacional, tanto no mercado nacional como internacional. Segundo Matten e Moon (2008), as empresas precisam estar atentas à RSC em duas frentes: i) implícita, no que tange aos valores, normas e regras referentes ao tema; e ii) explícita, que resulta das decisões da empresa em relação às questões percebidas como RSC.

Diversos autores reconhecem que a RSC pode representar um diferencial em relação aos concorrentes, um melhor posicionamento no mercado e até mesmo melhorar a performance financeira da empresa (Nidumolu, Prahalad, \& Rangaswami, 2009; Artiach, Lee, Nelson, \& Walker, 2010; Aguinis \& Glavas, 2012). Contudo, Kim, Kim e Qian (2018) argumentam que algumas descobertas inconsistentes em pesquisas anteriores indicam a necessidade de melhor se discutir os mecanismos pelos quais a RSC é traduzida em vantagens competitivas e melhoria de desempenho.

Visando atender tal lacuna, este artigo explora a relação entre a adoção de práticas ligadas à Responsabilidade Social Corporativa (RSC) e o desempenho financeiro e a imagem das empresas frente ao stakeholders (instituições, consumidores e acionistas). Foram realizadas pesquisas junto aos relatórios publicados pelas empresas listadas no Índice de Sustentabilidade Empresarial (ISE) da bolsa de valores nacional, a B3, resultante da fusão das atividades da BM\&FBOVESPA com a CETIP (Central de Custódia e Liquidação Financeira de Títulos) em Março/2017; à imprensa de negócios; e à literatura nacional e internacional sobre o tema.

O artigo está organizado nas seguintes seções: a partir da introdução e do objetivo aqui apresentados, apresenta-se uma fundamentação teórica sobre sustentabilidade empresarial, RSC e ISE. Em seguida, são detalhadas as etapas e procedimentos metodológicos utilizados para a realização da pesquisa. Com base nos relatórios das empresas listadas no ISE, na imprensa de negócios e na literatura, realiza-se a discussão acerca do conteúdo dos questionários aplicados pelo ISE 2017. Posteriormente, discute-se a relação entre as práticas de RSC e o desempenho das empresas, tanto financeiro, como também em termos da sua imagem frente ao mercado. Por fim, apresenta-se uma síntese dos resultados e as conclusões do estudo.

O debate sobre o tema não é novo - conforme Brunoro, Bolis, Pereira e Sznelwar (2013), o Relatório Brundtland de 1987 é considerado por muitos autores o marco da origem do conceito de Sustentabilidade Corporativa como hoje é conhecido -, mas está longe de ser concluído. Foi possível

OS, Organizações e Sustentabilidade, 7(2), p. 62-84, Londrina, PR, jul./dez. 2019 
identificar trabalhos que defendem visões bastante diferentes: alguns afirmam existir relação positiva entre a RSC e o desempenho das empresas, enquanto outros se posicionam de forma contrária. Além disso, alguns autores mantêm-se neutros, e outros argumentam haver simultaneamente efeitos positivos e negativos. De maneira geral, é possível perceber uma tendência à valorização dessas práticas sociais pelos consumidores e também pelos acionistas, visando benefícios e oportunidades que as mesmas podem trazer no futuro.

\section{SUSTENTABILIDADE EMPRESARIAL E RESPONSABILIDADE SOCIAL CORPORATIVA}

O conceito de sustentabilidade empresarial (SE) tem tido suas fronteiras ampliadas, podendo estar relacionado às esferas social, ambiental, econômica, espacial e urbana (Sachs, 1993). Também denominada por alguns autores como desenvolvimento empresarial sustentável, através da SE as empresas têm encontrado um importante meio de balancear os interesses próprios do mercado com as demandas de uma sociedade mais proativa em termos de maiores preocupações ambientais e sociais.

Do ponto de vista da estratégia competitiva adotada pelas empresas, a SE pode influenciar os níveis de satisfação do cliente e de consolidação no mercado. Nesse sentido, é possível contrapor dois tipos de visão empresarial: i) uma puramente focada em competitividade e; ii) outra que engloba a sustentabilidade, conforme mostra o Quadro 1:

\begin{tabular}{|c|c|c|}
\hline Visão empresarial & Competitividade & Visão empresarial \\
\hline Fatores considerados & Econômicos e operacionais & Fatores considerados \\
\hline Visão de mundo & $\begin{array}{c}\text { Restrita (empresa contra as } \\
\text { forças competitivas) }\end{array}$ & Visão de mundo \\
\hline $\begin{array}{c}\text { Significado da legislação } \\
\text { ambiental }\end{array}$ & $\begin{array}{c}\text { Aumento dos custos de produção } \\
\text { Processo de produção }\end{array}$ & \begin{tabular}{c} 
Significado da legislação ambiental \\
\hline Visão sobre o meio ambiente
\end{tabular} \\
\hline Visão empresarial & Ame tecnologias tradicionais & Processo de produção \\
\hline Fatores considerados & Econômicos e operacionais & Visão sobre o meio ambiente \\
\hline & Fonte: adaptado de Coral (2002) & Fisão empresarial \\
\hline
\end{tabular}

O mercado corporativo vem sendo constante e crescentemente desafiado por ações mais concretas relacionadas ao desenvolvimento social e ao uso eficiente de recursos naturais. Segundo Basseto (2010), esse novo cenário favorece as empresas consideradas "socialmente responsáveis" que passam a ser melhor avaliadas por seus investidores. Da mesma forma, os consumidores - internos e externos - passam a direcionar maior atenção às ações que promovem boas práticas ambientais e sociais.

As prestações de contas das empresas deixam de ser dirigidas somente aos seus acionistas e credores e passa a ser avaliada também por um amplo público - os stakeholders. Com os meios de comunicação mais acessiveis, principalmente por conta da internet, os stakeholders encontram um caminho muito mais curto tanto para reivindicar junto às empresas, assim como para cobrá-las ações socialmente responsáveis (Savitz \& Weber, 2007).

É importante ressaltar que, ao se tratar de estratégias sustentáveis, o resultado financeiro deixa de ser o único indicador de sucesso. Conforme Gomes e Tortato (2011), a gestão esclarecida e disciplinada dos impactos econômicos, sociais e ambientais, tornam-se um dos principais propósitos de interesse dos stakeholders e investidores que valorizam a sustentabilidade.

Nesse sentido, a responsabilidade social tem ganho grande espaço nas discussões sobre gestão empresarial, tornando-se assim um fator chave na formulação das estratégias organizacionais (Antoniolli \& Dias, 2013; Pacheco, Krüger, Lourenção, \& Caldana, 2016). Uma gestão socialmente

OS, Organizações e Sustentabilidade, 7(2), p. 62-84, Londrina, PR, jul./dez. 2019. 
responsável é aquela que traça seus objetivos e os operacionaliza, gerando retornos para os acionistas dentro das normas e éticas da sociedade. De acordo com Borger (2001), é possível que uma empresa assuma uma postura voltada para a responsabilidade social enquanto ainda mantém o foco nos objetivos financeiros ou nos interesses dos proprietários e acionistas. Para o autor, a responsabilidade social compreende atitudes e comportamentos relacionados ao desenvolvimento profissional, geração de empregos, combate à pobreza, valorização da diversidade, reciclagem e diminuição dos impactos ambientais, compromissos éticos e voluntariado.

Nesse cenário, a noção de Responsabilidade Social Corporativa (RSC) passa a ocupar uma posição de destaque nos meios político, empresarial e acadêmico. Quazi e O'Brien (2000) propuseram um modelo de RSC, conforme ilustra a Figura 1:

FIGURA 1 - MODELO DE RESPONSABILIDADE SOCIAL CORPORATIVA

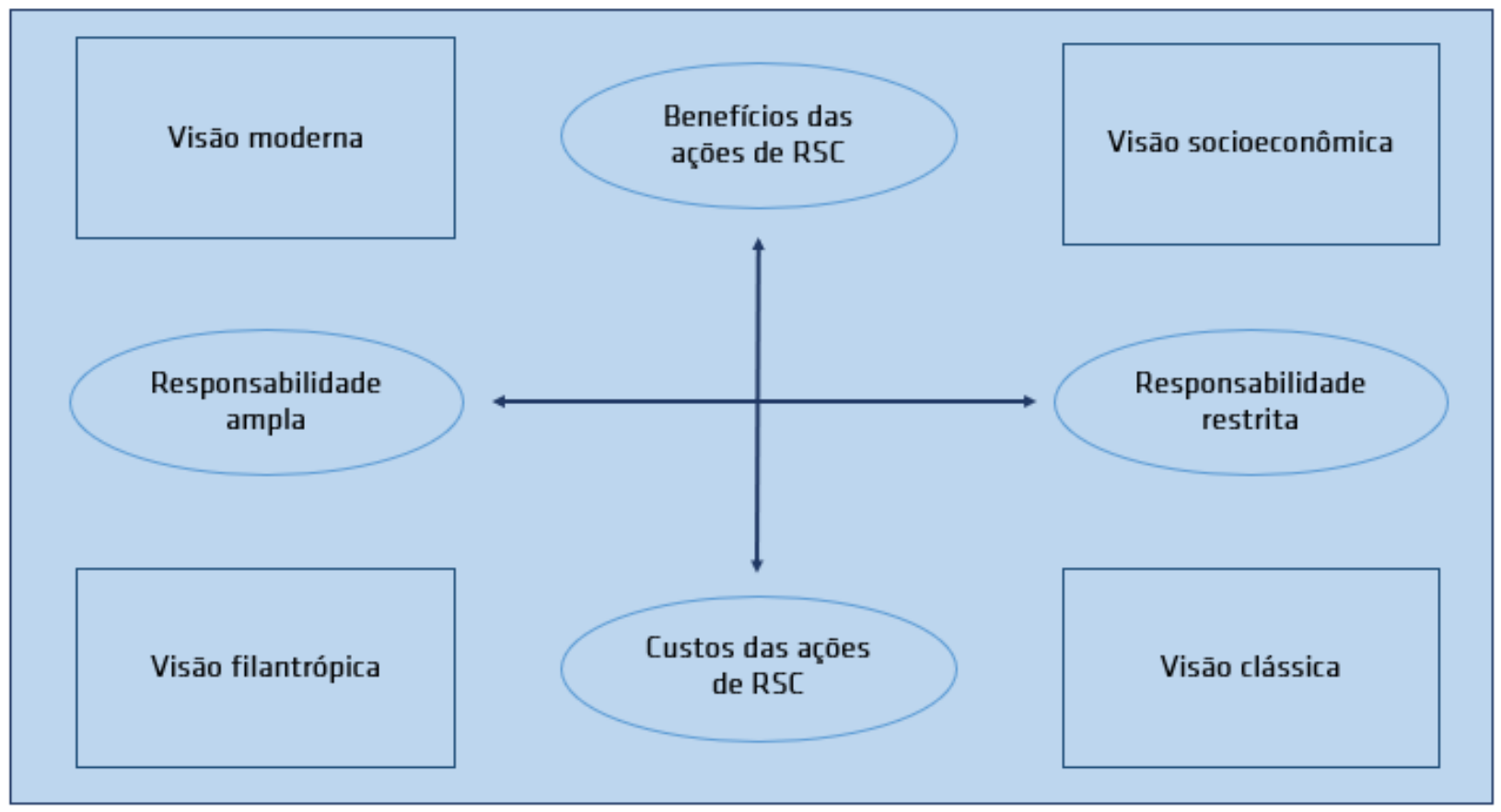

Fonte: Adaptado de Quazi e O’Brien (2000)

Cada um dos quadrantes do modelo representa uma visão, que podem ser assim descritas, conforme Comes, Souza, Coelho e Silva (2006): i) visão clássica: considera que as ações de RSC não geram valor; ii) socioeconômica: considera que a função-objetiva da empresa é a maximização do valor para o acionista, mas reconhecem que a RSC pode contribuir para a geração de valor; iii) filantrópica: defende as ações de RSC, mesmo que não tragam retorno; e iv) moderna: mantém ampla relação com a sociedade e traduz a RSC em benefícios de curto e longo prazos.

Frequentemente, a RSC e a SE são tratadas como sinônimos, porém, segundo Caldelli e Pamigiani (2004), existem diferenças importantes entre seus conceitos. Segundo os autores, a SE se refere à incorporação de aspectos sociais e ambientais no modelo de decisão das empresas, relacionando-se aos aspectos econômicos de maneira integrada e não conflitante. Assim, a SE pode ser entendida como uma forma de integração das questões socioambientais à estratégia corporativa. Tal integração pode ser usada sob a forma de vantagem competitiva sustentável (Wajnberg \& Leme, 2009). Por sua vez, a RSC se aproxima a uma filosofia, uma maneira de colocar-se frente aos impactos causados por uma organização à sociedade (Caldelli \& Pamigiani, 2004).

À medida que as empresas aliam suas estratégias de gestão ao tripé da sustentabilidade - que envolve desenvolvimento econômico, social e ambiental - favorecem a criação de novos modelos de negócios com foco no maior equilíbrio entre o capital social e o natural, associados ao

OS, Organizações e Sustentabilidade, 7(2), p. 62-84, Londrina, PR, jul./dez. 2019 
desenvolvimento de novas tecnologias e perspectivas coletivas (BM\&F Bovespa, 2016a). Assim, um novo modelo de empresa passa a se destacar; aquela que direciona seus esforços para minimizar os impactos ambientais e sociais, proporcionando adaptações em seus produtos, processos produtivos e estruturas administrativas, valorizando as diferentes atitudes dos diferentes atores (Schaltegger, Burritt, \& Petersen, 2003).

\section{INDICE DE SUSTENTABILIDADE EMPRESARIAL (ISE)}

Aplicadores e tomadores de recursos valorizam progressiva e crescentemente os Investimentos Socialmente Responsáveis (ISR), dessa forma, as empresas que combinam práticas de RSC e rentabilidade figuram como as opções mais atrativas junto a determinados grupos de investidores.

Segundo May, Lustosa e Vinha (2003), a criação de indicadores socioambientais corrobora a valorização de ações de empresas cuja gestão contempla a RSC no mercado de capitais nacional. Dentre os indicadores de maior credibilidade destaca-se o Índice de Sustentabilidade Empresarial (ISE), da Bolsa de Valores de São Paulo, e o Dow Jones Sustainability Index (DJSI), criado como forma de prêmio àquelas empresas que procuram alinhar a eficiência econômica à responsabilidade social.

O ISE foi criado nos moldes do DJSI e tem como propósito ser uma fonte segura para as demandas de desenvolvimento sustentável na sociedade estimulando a RSC através do equilíbrio entre os interesses sociais, econômicos e ambientais, proporcionando um ambiente seguro para investimentos do setor (BM\&F Bovespa, 2016a).

As empresas emissoras das 150 ações mais líquidas da BM\&F Bovespa participam desde 2005, de uma pesquisa anual que trata de aspectos financeiros, sociais, ambientais e de gestão. Para integrar a carteira do ISE, composta por até 40 empresas, as empresas candidatas devem participar do estudo acima, além de comprovar o atendimento aos pré-requisitos estabelecidos. No caso deste número ser ultrapassado são selecionadas aquelas com maior pontuação.

O instrumento de pesquisa utilizado pela B3 é um questionário desenvolvido pelo Centro de Estudos em Sustentabilidade da Fundação Getúlio Vargas que aborda sete dimensões: ambiental, social, econômico-financeira, governança corporativa, geral, natureza de produto e mudanças climáticas. A avaliação é realizada nos âmbitos quantitativo, pelas respostas do questionário, e qualitativo, com o envio de documentos que comprovem suas respostas (BM\&F Bovespa, 2016b).

No mês de novembro de 2017, a B3 anunciou a décima terceira carteira do ISE que vigorará até de janeiro de 2019. As empresas que compõem esta carteira envolvem 15 setores, somam $\mathrm{R} \$ 1,31$ trilhão em valor de mercado e representam $52,14 \%$ do total das companhias com ações na bolsa brasileira (BM\&F Bovespa, 2016b; B3, 2017a).

Esta carteira traz pela primeira vez a percepção dos Objetivos de Desenvolvimento Sustentável (ODS) adotados pela ONU no final de 2015. Estes ODS permitem que as empresas possam analisar de maneira mais integrada as implicações de suas práticas empresariais dentro de seus modelos de negócios além de possibilitar o traçado de metas e a previsão de indicadores com base nos resultados esperados para cada objetivo facilitando o desenvolvimento de recursos para o alcance de tais metas (BM\&F Bovespa, 2016a).

O principal objetivo do ISE é estimular boas práticas no meio empresarial e servir como uma referência segura para aqueles que buscam investir em empresas socialmente responsáveis. Dessa forma, o ISE funciona como um "selo de qualidade" dentro do mercado de capitais brasileiro e, futuramente, pretende-se despertar as boas práticas de responsabilidade social nas empresas que não possuem sua certificação (BM\&F Bovespa, 2016a).

OS, Organizações e Sustentabilidade, 7(2), p. 62-84, Londrina, PR, jul./dez. 2019.

ISSN 2318-9223, http://www.uel.br/revistas/uel/index.php/ros/issue/view/1607/showToc 


\section{METODOLOGIA}

Esta pesquisa pode ser classificada como uma revisão integrativa (Souza, Dias, \& Carvalho, 2010) que combina três instrumentos de coleta de dados: análise de relatórios publicados pelas empresas listadas no Índice de Sustentabilidade Empresarial (ISE) da BM\&F Bovespa, pesquisa junto à imprensa de negócios e análise da literatura.

Segundo Broome (1993), a revisão integrativa pode ser descrita como um método de revisão específico que examina a literatura científica sobre determinado tema, buscando fornecer uma melhor compreensão de um fenômeno particular. A revisão integrativa permite a inclusão de dados provenientes de estudos teóricos, empíricos, experimentais e não experimentais, mantendo o rigor metodológico das revisões sistemáticas (Whittemore \& Knafl, 2005). Conforme explicam Souza et al. (2010), este método proporciona a síntese de conhecimento sobre uma temática específica, visando identificar, analisar e sintetizar resultados de estudos independentes sobre o mesmo assunto.

Russell (2005) descreve as fases de uma revisão integrativa da seguinte maneira: formulação do problema; busca da literatura; avaliação dos dados; análise dos dados; interpretação e apresentação dos resultados. Com base nessa proposta, a revisão integrativa conduzida para esta pesquisa envolveu seis etapas distintas: i) definição do tema; ii) definição das fontes primárias; iii) estabelecimento de parâmetros para busca de artigos; iv) definição das informações a serem extraídas dos estudos selecionados; v) avaliação da amostra dos estudos incluídos; vi) interpretação e sintese dos resultados. A Figura 2 ilustra esse processo:

FIGURA 2 - Etapas e procedimentos METODOLÓGIcos da pesquisa

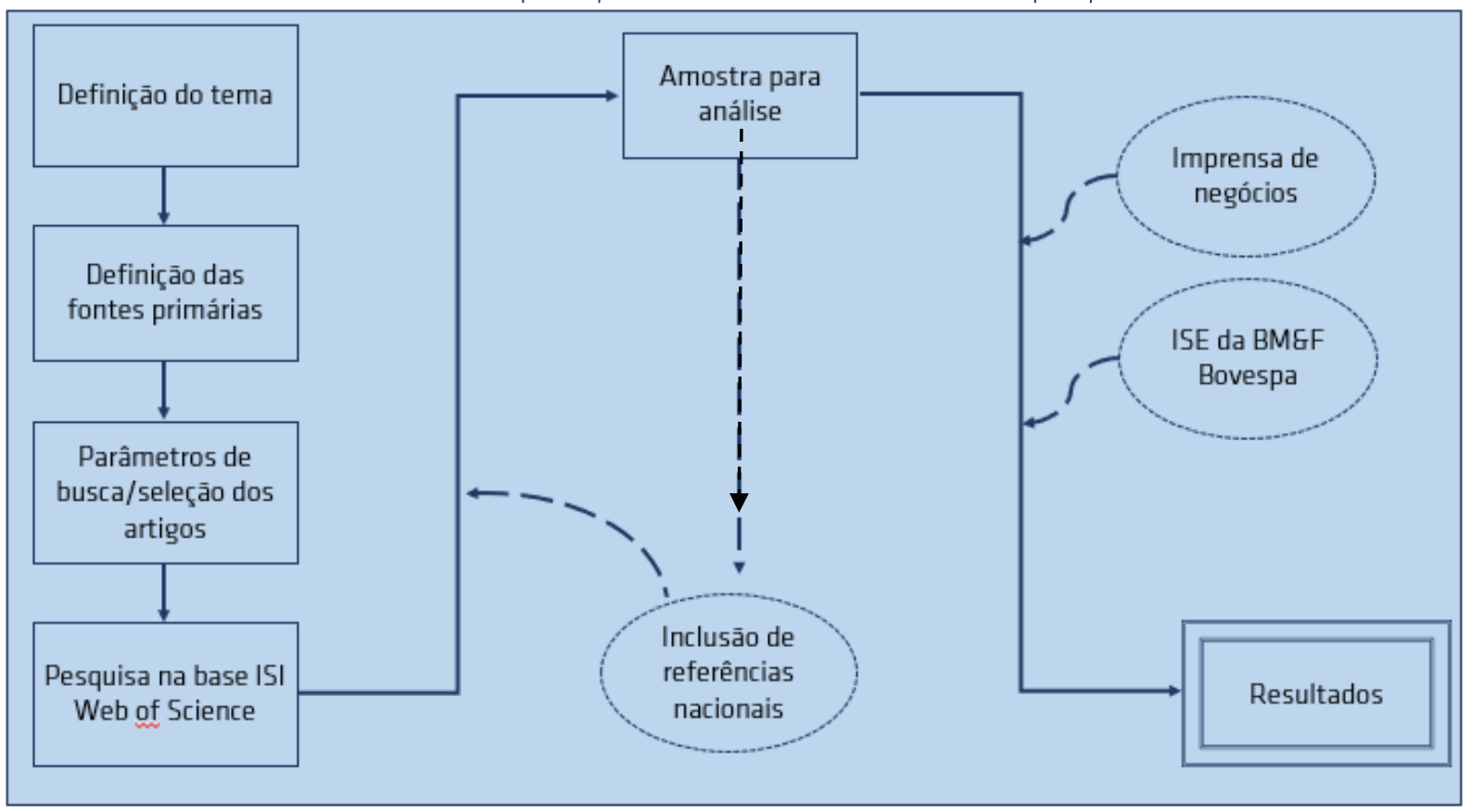

Fonte: elaborado pelos autores

Após a definição do tema (i), foram determinadas as referências primárias, úteis na definição do escopo do estudo (ii), assim como (iii) dos parâmetros para a realização da pesquisa bibliográfica. Foram utilizadas como fontes primárias artigos com elevado número de citações (e.g., Waddock \& Graves, 1997; Garriga \& Melé, 2004; Aguinis \& Glavas, 2012) e livros que abordassem o tema de forma abrangente (e.g., May, Lustosa, \& Vinha, 2003; Savitz \& Weber, 2007). Dessa forma, foram definidos os parâmetros de busca e seleção dos artigos, conforme mostra o Quadro 2: 
QUADRO 2 - PARÂMETROS DE BUSCA E SELEÇÃO DE ARTIGOS PARA ANÁLISE

\begin{tabular}{|c|c|}
\hline Parâmetro & Descrição \\
\hline Questão a ser respondida & $\begin{array}{l}\text { Quais os efeitos da adoção de práticas ligadas à RSC sobre o desempenho } \\
\text { financeiro e a imagem das empresas frente aos stakeholders? }\end{array}$ \\
\hline Fontes primárias & $\begin{array}{c}\text { Waddock e Graves (1997), May et al. (2003), Garriga e Melé (2004), Savitz e } \\
\text { Weber (2007), Aguinis e Glavas (2012) }\end{array}$ \\
\hline Palavras-chave & Responsabilidade Social Corporativa; Índice de Sustentabilidade Empresarial \\
\hline Ano de publicação & Todos os anos \\
\hline Áreas de pesquisa & Engenharia; Ciências Econômicas e Contábeis; Administração; Gestão \\
\hline Critérios de inclusão & Tipo de documento (somente artigos publicados em periódicos) \\
\hline Critério de qualificação & $\begin{array}{c}\text { O artigo deve abordar pelo menos um dos seguintes tópicos: } \\
\text { • RSC enquanto vantagem competitiva } \\
\text { • Influência da RSC na imagem frente ao mercado } \\
\text { - Relação da RSC com o desempenho financeiro } \\
\text { • Ampla revisão da literatura e framework } \\
\text { - Perfil das empresas que adotam práticas de RSC }\end{array}$ \\
\hline
\end{tabular}

Fonte: elaborado pelos autores

Com base nesses parâmetros, realizou-se a busca de artigos na base ISI Web of Science. Como indica o Quadro 2, os documentos foram submetidos aos seguintes filtros: área de pesquisa, tipo de documentos (critério de inclusão) e tópico abordado (critério de qualificação), resultando em 22 artigos publicados em periódicos de alto impacto (Quadro 3): 
Vantagens Competitivas Associadas à Adoção da Responsabilidade Social Corporativa e à Participação no Índice de Sustentabilidade Empresarial

QUADRO 3 - ARTIGOS DA BASE ISI WEB OF SCIENCE SELECIONADOS

\begin{tabular}{|c|c|c|c|c|c|}
\hline N. & Autoria & Título & Periódico & $\underset{(2016)}{J C R}$ & $\begin{array}{l}\text { Cita- } \\
\text { ções }\end{array}$ \\
\hline 1 & $\begin{array}{c}\text { Alexander e } \\
\text { Buchholz (1978) }\end{array}$ & $\begin{array}{c}\text { Corporate Social Responsibility and Stock } \\
\text { Market Performance }\end{array}$ & $\begin{array}{c}\text { Academy of } \\
\text { Management Journal }\end{array}$ & 7,417 & 196 \\
\hline 2 & Ullman (1985) & $\begin{array}{l}\text { Data in Search of a Theory: A Critical } \\
\text { Examination of the Relationships Among } \\
\text { Social Performance, Social Disclosure, and } \\
\text { Economic Performance of U.S. Firms. }\end{array}$ & $\begin{array}{l}\text { Academy of } \\
\text { Management } \\
\text { Review }\end{array}$ & 9,408 & 672 \\
\hline 3 & $\begin{array}{l}\text { Aupperle, Carroll e } \\
\text { Hatfield (1985) }\end{array}$ & $\begin{array}{c}\text { An Empirical Examination of the Relationship } \\
\text { Between Corporate Social Responsibility and } \\
\text { Profitability }\end{array}$ & $\begin{array}{l}\text { Academy of } \\
\text { Management Journal }\end{array}$ & 7,417 & 651 \\
\hline 4 & $\begin{array}{l}\text { McGuire, Sundgren e } \\
\text { Schneeweis (1988) }\end{array}$ & $\begin{array}{c}\text { Corporate Social Responsibility and Firm } \\
\text { Financial Performance }\end{array}$ & $\begin{array}{c}\text { Academy of } \\
\text { Management Journal }\end{array}$ & 7,417 & 824 \\
\hline 5 & $\begin{array}{c}\text { Waddock e Graves } \\
\text { (1997) }\end{array}$ & $\begin{array}{c}\text { The Corporate Social Performance - Financial } \\
\text { Performance Link }\end{array}$ & $\begin{array}{c}\text { Strategic } \\
\text { Management Journal }\end{array}$ & 4,461 & 1.638 \\
\hline 6 & $\begin{array}{l}\text { Caldelli e Parmigiani } \\
\qquad(2004)\end{array}$ & $\begin{array}{l}\text { Management Information System: a Tool for } \\
\text { Corporate Sustainability }\end{array}$ & $\begin{array}{l}\text { Journal of Business } \\
\text { Ethics }\end{array}$ & 2,354 & 16 \\
\hline 7 & $\begin{array}{l}\text { Garriga e Melé } \\
(2004)\end{array}$ & $\begin{array}{c}\text { Corporate Social Responsibility theories: } \\
\text { Mapping the territory }\end{array}$ & $\begin{array}{c}\text { Journal of Business } \\
\text { Ethics }\end{array}$ & 2,354 & 923 \\
\hline 8 & $\begin{array}{l}\text { Igalens e Gond } \\
\quad(2005)\end{array}$ & $\begin{array}{c}\text { Measuring Corporate Social Performance in } \\
\text { France: a critical and empirical analysis of } \\
\text { ARESE data }\end{array}$ & $\begin{array}{c}\text { Journal of Business } \\
\text { Ethics }\end{array}$ & 2,354 & 68 \\
\hline 9 & Barnett (2005) & $\begin{array}{c}\text { Stakeholder Influence Capacity and the } \\
\text { Variability of Financial Returns to Corporate } \\
\text { Social Responsibility }\end{array}$ & $\begin{array}{l}\text { Academy of } \\
\text { Management } \\
\text { Review }\end{array}$ & 9,408 & 445 \\
\hline 10 & $\begin{array}{l}\text { Becchetti, Giacomo e } \\
\text { Pinnacchio (2008) }\end{array}$ & $\begin{array}{l}\text { Corporate Social Responsibility and Corporate } \\
\text { Performance: Evidence from a Panel of U.S. }\end{array}$ & Applied Economics & 0,648 & 30 \\
\hline 11 & $\begin{array}{l}\text { Matten e Moon } \\
\quad(2008)\end{array}$ & $\begin{array}{l}\text { "Implicit" and "explicit" CSR: A conceptual } \\
\text { framework for a comparative understanding } \\
\text { of corporate social responsibility }\end{array}$ & $\begin{array}{l}\text { Academy of } \\
\text { Management } \\
\text { Review }\end{array}$ & 9,408 & 983 \\
\hline 12 & $\begin{array}{l}\text { Sakuma e Louche } \\
\text { (2008) }\end{array}$ & $\begin{array}{l}\text { Socially Responsible Investment in Japan: its } \\
\text { mechanism and drivers. }\end{array}$ & $\begin{array}{c}\text { Journal of Business } \\
\text { Ethics }\end{array}$ & 2,354 & 14 \\
\hline 13 & $\begin{array}{l}\text { Jones, Laan, Frost e } \\
\text { Loftus (2008) }\end{array}$ & $\begin{array}{l}\text { The investment performance of Socially } \\
\text { Responsible Investment Funds in Australia. }\end{array}$ & $\begin{array}{c}\text { Journal of Business } \\
\text { Ethics }\end{array}$ & 2,354 & 31 \\
\hline 14 & $\begin{array}{l}\text { Nidumolu, Prahalad } \\
\text { e Rangaswami } \\
\text { (2009) }\end{array}$ & $\begin{array}{l}\text { Why Sustainability Is Now the Key Driver of } \\
\text { Innovation? }\end{array}$ & $\begin{array}{l}\text { Harvard Business } \\
\text { Review }\end{array}$ & 3,227 & 322 \\
\hline 15 & $\begin{array}{c}\text { Clarkson, Li, } \\
\text { Richardson e Vasvari } \\
\text { (2010) }\end{array}$ & $\begin{array}{l}\text { Does It Really Pay to Be Green? Determinants } \\
\text { and Consequences of Proactive Environmental } \\
\text { Strategies. }\end{array}$ & $\begin{array}{l}\text { Journal of } \\
\text { Accounting and } \\
\text { Public Policy }\end{array}$ & 1,333 & 132 \\
\hline 16 & $\begin{array}{l}\text { Artiach, Lee, Nelson } \\
\text { e Walker (2010) }\end{array}$ & $\begin{array}{l}\text { The Determinants of Corporate Sustainability } \\
\text { Performance }\end{array}$ & $\begin{array}{l}\text { Accounting \& } \\
\text { Finance }\end{array}$ & 1,396 & 76 \\
\hline 17 & $\begin{array}{l}\text { Aguinis e Glavas } \\
\qquad(2012)\end{array}$ & $\begin{array}{c}\text { What We Know and Don't Know About } \\
\text { Corporate Social Responsibility: A Review and } \\
\text { Research Agenda }\end{array}$ & $\begin{array}{l}\text { Journal of } \\
\text { Management }\end{array}$ & 7,733 & 494 \\
\hline 18 & Hiss (2013) & $\begin{array}{c}\text { The Politics of the Financialization of } \\
\text { Sustainability }\end{array}$ & $\begin{array}{l}\text { Competition \& } \\
\text { Change }\end{array}$ & 1,81 & 8 \\
\hline 19 & $\begin{array}{l}\text { Navarro, Reverte, } \\
\text { Melero e Wensley } \\
\text { (2016) }\end{array}$ & $\begin{array}{l}\text { Linking social and economic responsibilities } \\
\text { with financial performance: The role of } \\
\text { innovation. }\end{array}$ & $\begin{array}{l}\text { European } \\
\text { Management Journal }\end{array}$ & 2,481 & 2 \\
\hline 20 & Wang e Sarkis (2017) & $\begin{array}{l}\text { Corporate Social Responsibility Governance, } \\
\text { Outcomes, and Financial Performance. }\end{array}$ & $\begin{array}{l}\text { Journal of Cleaner } \\
\text { Production }\end{array}$ & 5,715 & 2 \\
\hline 21 & $\begin{array}{l}\text { Austin e Gaither } \\
\text { (2017) }\end{array}$ & $\begin{array}{c}\text { Perceived motivations for corporate social } \\
\text { responsibility initiatives in social stigmatized } \\
\text { industries }\end{array}$ & $\begin{array}{l}\text { Public Relations } \\
\text { Review }\end{array}$ & 1,311 & 0 \\
\hline 22 & $\begin{array}{l}\text { Kim, Kim e Qian } \\
\text { (2018) }\end{array}$ & $\begin{array}{c}\text { Effects of Corporate Social Responsibility on } \\
\text { Corporate Financial Performance: A } \\
\text { Competitive-Action Perspective }\end{array}$ & $\begin{array}{l}\text { Journal of } \\
\text { Management }\end{array}$ & 7,733 & 3 \\
\hline
\end{tabular}

Fonte: elaborado pelos autores

OS, Organizações e Sustentabilidade, 7(2), p. 62-84, Londrina, PR, jul./dez. 2019

ISSN 2318-9223, http://www.uel.br/revistas/uel/index.php/ros/issue/view/1607/showToc 
Visando às pesquisas relacionadas ao ISE da B3, procedeu-se à busca de estudos nacionais sobre o tema na base Scielo, empregando-se os mesmos critérios de busca, incluindo-se 20 artigos para análise. Além disso, também foram incluídas fontes relevantes no formato de livros. 0 Quadro 4 reúne as referências selecionadas nessa etapa: 
Vantagens Competitivas Associadas à Adoção da Responsabilidade Social Corporativa e à Participação no Índice de Sustentabilidade Empresarial

\begin{tabular}{|c|c|c|c|}
\hline No. & Autoria & Título & Periódico/Tipo \\
\hline 23 & Jeucken (2001) & $\begin{array}{l}\text { Sustainable Finance and Banking: the financial sector and } \\
\text { the future of the planet }\end{array}$ & Livro \\
\hline 24 & $\begin{array}{l}\text { May, Lustosa e Vinha } \\
\text { (2003) }\end{array}$ & Economia do meio ambiente: teoria e prática & Livro \\
\hline 25 & Savitz e Weber (2007) & $\begin{array}{l}\text { A empresa sustentável: o verdadeiro sucesso é o lucro com } \\
\text { responsabilidade social e ambiental }\end{array}$ & Livro \\
\hline 26 & $\begin{array}{l}\text { Machado Filho e } \\
\text { Zylbersztajn (2004) }\end{array}$ & $\begin{array}{l}\text { A Empresa Socialmente Responsável: o Debate e as } \\
\text { Implicações }\end{array}$ & $\begin{array}{c}\text { Revista de } \\
\text { Administração da USP }\end{array}$ \\
\hline 27 & Ferreira (2004) & $\begin{array}{l}\text { Responsabilidade social, governança corporativa e valor das } \\
\text { empresas }\end{array}$ & $\begin{array}{c}\text { Revista de } \\
\text { Administração da UFLA }\end{array}$ \\
\hline 28 & $\begin{array}{l}\text { Esteves, Silva e Aligleri } \\
\qquad(2007)\end{array}$ & $\begin{array}{c}\text { Gestão estratégica da responsabilidade social: o caso das } \\
\text { empresas do setor de atacado e comércio exterior na } \\
\text { Região Sul do País }\end{array}$ & Revista da FAE \\
\hline 29 & $\begin{array}{l}\text { Rezende, Nunes e } \\
\text { Portela (2008) }\end{array}$ & $\begin{array}{l}\text { Um Estudo sobe o desempenho financeiro do Índice } \\
\text { Bovespa de Sustentabilidade Empresarial }\end{array}$ & $\begin{array}{l}\text { Revista de Educação e } \\
\text { Pesquisa em } \\
\text { Contabilidade }\end{array}$ \\
\hline 30 & Milani Filho (2008) & $\begin{array}{c}\text { Responsabilidade Social e Investimento Social Privado: } \\
\text { Entre o Discurso e a Evidenciação }\end{array}$ & $\begin{array}{l}\text { Revista Contabilidade \& } \\
\text { Finanças }\end{array}$ \\
\hline 31 & $\begin{array}{l}\text { Silva, Rocha, Wienhage } \\
\text { e Rausch (2009) }\end{array}$ & $\begin{array}{c}\text { Gestão Ambiental: uma análise da Evidenciação das } \\
\text { Empresas que compõem o ISE }\end{array}$ & $\begin{array}{l}\text { Revista de Gestão Social } \\
\text { e Ambiental }\end{array}$ \\
\hline 32 & $\begin{array}{l}\text { Machado, Machado e } \\
\quad \text { Corrar (2009) }\end{array}$ & $\begin{array}{c}\text { Desempenho do Îndice de Sustentabilidade Empresarial da } \\
\text { Bolsa de Valores de São Paulo. }\end{array}$ & $\begin{array}{l}\text { Revista Universo } \\
\text { Contábil }\end{array}$ \\
\hline 33 & $\begin{array}{l}\text { Figueiredo, Abreu e } \\
\quad \text { Casas (2009) }\end{array}$ & $\begin{array}{l}\text { Reflexos do Índice de Sustentabilidade Empresarial (ISE) na } \\
\text { Imagem das Empresas: uma Análise do Consumidor } \\
\text { Consciente e do Marketing Ambiental }\end{array}$ & $\begin{array}{l}\text { Pensamento \& } \\
\text { Realidade }\end{array}$ \\
\hline 34 & $\begin{array}{l}\text { Wajnberg e Leme } \\
\text { (2009) }\end{array}$ & $\begin{array}{c}\text { Exame Da Divulgação Do Relacionamento Entre Iniciativas } \\
\text { Socioambientais e Desempenho Financeiro Corporativo Nos } \\
\text { Bancos Brasileiros }\end{array}$ & $\begin{array}{l}\text { Revista de Gestão Social } \\
\text { e Ambiental }\end{array}$ \\
\hline 35 & $\begin{array}{l}\text { Nunes, Teixeira, Nossa } \\
\quad \text { e Caldi (2010) }\end{array}$ & $\begin{array}{c}\text { Análise das variáveis que influenciam a adesão das } \\
\text { empresas ao índice BMধF Bovespa de Sustentabilidade } \\
\text { Empresarial. }\end{array}$ & $\begin{array}{l}\text { Revista de } \\
\text { Administração e } \\
\text { Contabilidade da } \\
\text { Unisinos }\end{array}$ \\
\hline 36 & Basseto (2010) & $\begin{array}{l}\text { A incorporação da responsabilidade social e } \\
\text { sustentabilidade: um estudo baseado no relatório de } \\
\text { gestão } 2005 \text { da companhia paranaense de energia }\end{array}$ & Gestão \& Produção \\
\hline 37 & $\begin{array}{l}\text { Teixeira, Nossa e } \\
\text { Funchal (2011) }\end{array}$ & $\begin{array}{l}\text { O índice de sustentabilidade empresarial (ISE) e os } \\
\text { impactos no endividamento e na percepção de risco }\end{array}$ & $\begin{array}{l}\text { Revista Contabilidade \& } \\
\quad \text { Finanças }\end{array}$ \\
\hline 38 & Gomes e Tortato (2011) & $\begin{array}{l}\text { Adoção de Práticas de Sustentabilidade como Vantagem } \\
\text { Competitiva: Evidências Empíricas }\end{array}$ & $\begin{array}{l}\text { Revista Pensamento } \\
\text { Contemporâneo em } \\
\text { Administração }\end{array}$ \\
\hline 39 & Costa e Boente (2011) & $\begin{array}{l}\text { Avaliação da eficiência econômico-financeira das empresas } \\
\text { integrantes do ISE por meio da análise envoltória de dados }\end{array}$ & $\begin{array}{l}\text { Revista Ambiente } \\
\text { Contábil }\end{array}$ \\
\hline 40 & $\begin{array}{l}\text { Andrade, Bressan, } \\
\text { Iquiapaza e Moreira } \\
\text { (2013) }\end{array}$ & $\begin{array}{l}\text { Determinantes de Adesão ao ISE da BMGF Bovespa e sua } \\
\text { relação com o valor da empresa }\end{array}$ & $\begin{array}{l}\text { Revista Brasileira de } \\
\text { Finanças }\end{array}$ \\
\hline 41 & Antoniolli e Dias (2013) & $\begin{array}{c}\text { A Evolução da Responsabilidade Corporativa em Empresa } \\
\text { do Setor Elétrico Brasileiro: um Estudo de Caso }\end{array}$ & $\begin{array}{l}\text { Organizações \& } \\
\text { Sustentabilidade }\end{array}$ \\
\hline 42 & Benites e Polo (2013) & $\begin{array}{l}\text { A sustentabilidade como ferramenta estratégia } \\
\text { empresarial: governança corporativa e aplicação do Triple } \\
\text { Bottom Line na massa }\end{array}$ & $\begin{array}{c}\text { Revista de } \\
\text { Administração da UFSM }\end{array}$ \\
\hline 43 & $\begin{array}{l}\text { Pacheco, Krüger, } \\
\text { Lourenção e Caldana } \\
\text { (2016) }\end{array}$ & $\begin{array}{c}\text { A Evolução da Responsabilidade Corporativa em Empresa } \\
\text { do Setor Elétrico Brasileiro: um Estudo de Caso }\end{array}$ & $\begin{array}{l}\text { Organizações \& } \\
\text { Sustentabilidade }\end{array}$ \\
\hline 44 & Sartore (2016) & $\begin{array}{c}\text { A difusão do Investimento Sustentável: reflexões a partir } \\
\text { da Iniciativa para a Bolsa de Valores Sustentável }\end{array}$ & Política \& Sociedade \\
\hline 45 & $\begin{array}{l}\text { Vasconcelos e } \\
\text { Hourneaux Júnior (2017) }\end{array}$ & $\begin{array}{c}\text { As Práticas Sustentáveis nas Organizações e a Geração de } \\
\text { Valor para o Investidor Institucional }\end{array}$ & $\begin{array}{l}\text { Organizações \& } \\
\text { Sustentabilidade }\end{array}$ \\
\hline
\end{tabular}

Fonte: elaborado pelos autores

OS, Organizações e Sustentabilidade, 7(2), p. 62-84, Londrina, PR, jul./dez. 2019

ISSN 2318-9223, http://www.uel.br/revistas/uel/index.php/ros/issue/view/1607/showToc 
Finalmente, a última etapa consistiu na análise dos 45 estudos selecionados (Quadros 3 e 4), realizando-se a triangulação dos dados com documentos do ISE na B3 e da imprensa de negócios, cujos resultados estão apresentados nas seções seguintes.

\section{RESULTADOS}

O Quadro 5 mostra os estudos que abordam, prioritariamente, um dos tópicos relacionados ao tema do presente trabalho:

QUADRO 5 - TÓPICOS ABORDADOS E REFERÊNCIAS EQUIVALENTES

\begin{tabular}{|c|c|}
\hline Tópico abordado no estudo & Referências \\
\hline Perfil das empresas que adotam práticas de RSC & $6,20,21,28,31,34,36,40,42$ \\
\hline Perspectivas financeiras: relação positiva & $4,5,8,9,12,13,15,16,18,22,24,25,34,37,38$, \\
40,43
\end{tabular}

Fonte: elaborado pelos autores

Inicialmente, com base nos dados divulgados pela B3, são analisados os questionários preenchidos pelas empresas elegidas na carteira do ISE 2017. Em seguida, são discutidas as vantagens competitivas possibilitadas pela adoção de práticas ligadas à RSC e sua influência no desempenho financeiro e na imagem frente aos stakeholders.

\section{INDICE DE SUSTENTABILIDADE EMPRESARIAL DA B3}

Em Novembro de 2017, a B3 anunciou a décima terceira carteira do Índice de Sustentabilidade Empresarial (ISE) que irá vigorar de 02 de Janeiro de 2018 até 04 de Janeiro de 2019 (B3, 2017a). A nova carteira do ISE, que desde sua criação conta com o apoio técnico do Centro de Estudos em Sustentabilidade da FGV (FGVces), reúne 33 ações de 30 empresas que representam 12 setores, somando R\$ 1,28 trilhão em valor de mercado, montante que representa $41,47 \%$ do total das empresas listadas na B3 (B3, 2017a). Para montar a carteira do ISE, foram convidadas 179 companhias, emissoras das 200 ações mais líquidas na B3, e destas, 41 se inscreveram no processo, sendo 37 elegiveis, três na carteira Simulado e uma Treineira (B3, 2017a, 2017c).

Na edição de 2018, 100\% das empresas das carteiras que compõem o índice, aderiram formal e publicamente aos compromissos voluntários relacionados ao desenvolvimento sustentável. Em 2015 e 2016, respectivamente, $93 \%$ e $97 \%$ das empresas firmaram tais compromissos. Em 2017, ainda, todas as empresas da carteira publicaram seus relatórios de sustentabilidade no modelo internacional (Global Reporting Initiative - GRI) declarando formalmente seu compromisso em relação às mudanças climáticas. 95\% destas empresas possuem uma diretoria dedicada às questões de sustentabilidade que se reporta diretamente à alta direção (em 2016 eram 93\% e em 2015, 92\%).

Para a formação da carteira ISE 2018, a BM\&F Bovespa enviou o questionário para 179 empresas que aspiravam entrar para o ISE. O Quadro 6 mostra as categorias de classificação e as respectivas quantidades de empresas elegiveis:

OS, Organizações e Sustentabilidade, 7(2), p. 62-84, Londrina, PR, jul./dez. 2019. 


\begin{tabular}{|c|c|c|}
\hline Categoria & Descrição & $\begin{array}{l}\text { Empresas } \\
\text { elegiveis }\end{array}$ \\
\hline Consumo cíclico & $\begin{array}{c}\text { Empresas que dependem de um determinado ciclo da economia para } \\
\text { obterem ganhos mais expressivos (e.g., comércio/varejo, hotéis, } \\
\text { calçados, lazer) }\end{array}$ & 31 \\
\hline Bens industriais & $\begin{array}{c}\text { Responsáveis por produtos que são usados na produção de outros } \\
\text { bens (e.g. matéria-prima, máquinas, ferramentas) }\end{array}$ & 27 \\
\hline Financeira & Bancos, seguradoras, empresas de investimento, financiadoras & 21 \\
\hline Utilidade pública & $\begin{array}{c}\text { Empresas de saneamento, distribuição e tratamento de água e } \\
\text { distribuição de energia elétrica }\end{array}$ & 21 \\
\hline Materiais básicos & Siderúrgicas, indústrias de papel e celulose e minerais & 12 \\
\hline Consumo não-cíclico & $\begin{array}{c}\text { Empresas menos afetadas em épocas de crise (e.g., alimentos, } \\
\text { fumo, bebidas) }\end{array}$ & 12 \\
\hline Construção civil & Construtoras e incorporadora & 10 \\
\hline Saúde & Planos de saúde, redes de diagnóstico e farmácias & 9 \\
\hline $\begin{array}{l}\text { Exploração de } \\
\text { imóveis }\end{array}$ & Redes de shoppings e outros conglomerados imobiliários & 7 \\
\hline $\begin{array}{l}\text { Tecnologia da } \\
\text { Informação }\end{array}$ & Empresas de serviços e desenvolvimento tecnológicos & 5 \\
\hline Petróleo e gás & Exploração e produção de combustiveis & 5 \\
\hline $\begin{array}{l}\text { Serviços } \\
\text { educacionais }\end{array}$ & Empresas e conglomerados com foco na educação & 4 \\
\hline Agricultura & Agroindústria e pecuária & 3 \\
\hline Telecomunicação & Empresas e conglomerados de comunicação & 3 \\
\hline
\end{tabular}

Fonte: elaborado pelos autores

O Quadro 7 mostra as empresas que figuraram em todas as edições do ISE publicadas até o momento da realização do presente estudo, isto é, de 2006 até 2018: 
QUADRO 7 - COMPOSIÇÃO DAS CARTEIRAS DO ISE ENTRE 2005 E 2018

\begin{tabular}{|c|c|c|c|c|c|c|c|c|c|c|c|c|c|}
\hline \multirow[t]{2}{*}{ Empresa } & \multicolumn{13}{|c|}{ Carteira do ISE } \\
\hline & 2006 & 2007 & 2008 & 2009 & 2010 & 2011 & 2012 & 2013 & 2014 & 2015 & 2016 & 2017 & 2018 \\
\hline Acesita & & $\checkmark$ & $\checkmark$ & & & & & & & & & & \\
\hline AES Tietê & & & $\checkmark$ & $\checkmark$ & $\checkmark$ & $\checkmark$ & $\checkmark$ & $\checkmark$ & $\checkmark$ & $\checkmark$ & $\checkmark$ & $\checkmark$ & $\checkmark$ \\
\hline ALL America Latina & $\checkmark$ & $\checkmark$ & & & & & & & & & & & \\
\hline Anhanguera & & & & & & $\checkmark$ & $\checkmark$ & & & & & & \\
\hline Aracruz & $\checkmark$ & $\checkmark$ & $\checkmark$ & & & & & & & & & & \\
\hline Arcelor BR & & $\checkmark$ & & & & & & & & & & & \\
\hline B2W & & & & & & & & & & $\checkmark$ & $\checkmark$ & $\checkmark$ & $\checkmark$ \\
\hline Banco do Brasil & $\checkmark$ & $\checkmark$ & $\checkmark$ & $\checkmark$ & & & $\checkmark$ & $\checkmark$ & $\checkmark$ & $\checkmark$ & $\checkmark$ & $\checkmark$ & $\checkmark$ \\
\hline Belgo Mineira & $\checkmark$ & & & & & & & & & & & & \\
\hline Bicbanco & & & & & & $\checkmark$ & $\checkmark$ & $\checkmark$ & $\checkmark$ & $\checkmark$ & & & \\
\hline Bradesco & $\checkmark$ & & $\checkmark$ & $\checkmark$ & $\checkmark$ & $\checkmark$ & $\checkmark$ & $\checkmark$ & $\checkmark$ & $\checkmark$ & $\checkmark$ & $\checkmark$ & $\checkmark$ \\
\hline Brasil & & & & & $\checkmark$ & $\checkmark$ & & & & & & & \\
\hline Braskem & $\checkmark$ & $\checkmark$ & $\checkmark$ & $\checkmark$ & $\checkmark$ & $\checkmark$ & $\checkmark$ & $\checkmark$ & $\checkmark$ & $\checkmark$ & $\checkmark$ & $\checkmark$ & $\checkmark$ \\
\hline BRF & & & & & $\checkmark$ & $\checkmark$ & $\checkmark$ & $\checkmark$ & $\checkmark$ & $\checkmark$ & $\checkmark$ & $\checkmark$ & \\
\hline CCR & $\checkmark$ & $\checkmark$ & $\checkmark$ & & & & $\checkmark$ & $\checkmark$ & $\checkmark$ & $\checkmark$ & $\checkmark$ & $\checkmark$ & $\checkmark$ \\
\hline Celesc & $\checkmark$ & $\checkmark$ & & $\checkmark$ & & & & & & & & $\checkmark$ & $\checkmark$ \\
\hline Cemig & $\checkmark$ & $\checkmark$ & $\checkmark$ & $\checkmark$ & $\checkmark$ & $\checkmark$ & $\checkmark$ & $\checkmark$ & $\checkmark$ & $\checkmark$ & $\checkmark$ & $\checkmark$ & $\checkmark$ \\
\hline Cesp & $\checkmark$ & & $\checkmark$ & $\checkmark$ & $\checkmark$ & $\checkmark$ & $\checkmark$ & $\checkmark$ & $\checkmark$ & & $\checkmark$ & & \\
\hline Cielo & & & & & & & & & $\checkmark$ & $\checkmark$ & $\checkmark$ & $\checkmark$ & $\checkmark$ \\
\hline Coelce & & $\checkmark$ & $\checkmark$ & $\checkmark$ & $\checkmark$ & $\checkmark$ & $\checkmark$ & $\checkmark$ & $\checkmark$ & $\checkmark$ & & & \\
\hline Copasa & & & & & & $\checkmark$ & $\checkmark$ & $\checkmark$ & $\checkmark$ & & & & \\
\hline Copel & $\checkmark$ & $\checkmark$ & $\checkmark$ & & $\checkmark$ & $\checkmark$ & $\checkmark$ & $\checkmark$ & $\checkmark$ & $\checkmark$ & $\checkmark$ & $\checkmark$ & $\checkmark$ \\
\hline Copesul & $\checkmark$ & & & & & & & & & & & & \\
\hline CPFL & $\checkmark$ & $\checkmark$ & $\checkmark$ & $\checkmark$ & $\checkmark$ & $\checkmark$ & $\checkmark$ & $\checkmark$ & $\checkmark$ & $\checkmark$ & $\checkmark$ & $\checkmark$ & $\checkmark$ \\
\hline DASA & $\checkmark$ & $\checkmark$ & $\checkmark$ & $\checkmark$ & $\checkmark$ & & & & & & & & \\
\hline Duratex & & & & $\checkmark$ & $\checkmark$ & $\checkmark$ & $\checkmark$ & $\checkmark$ & $\checkmark$ & $\checkmark$ & $\checkmark$ & $\checkmark$ & $\checkmark$ \\
\hline Ecorodovias & & & & & & & $\checkmark$ & $\checkmark$ & $\checkmark$ & $\checkmark$ & $\checkmark$ & $\checkmark$ & $\checkmark$ \\
\hline EDP & & $\checkmark$ & $\checkmark$ & $\checkmark$ & $\checkmark$ & $\checkmark$ & $\checkmark$ & $\checkmark$ & $\checkmark$ & $\checkmark$ & $\checkmark$ & $\checkmark$ & $\checkmark$ \\
\hline Eletrobrás & $\checkmark$ & & $\checkmark$ & $\checkmark$ & $\checkmark$ & $\checkmark$ & $\checkmark$ & $\checkmark$ & $\checkmark$ & $\checkmark$ & $\checkmark$ & $\checkmark$ & \\
\hline Eletropaulo & $\checkmark$ & $\checkmark$ & $\checkmark$ & $\checkmark$ & $\checkmark$ & $\checkmark$ & $\checkmark$ & $\checkmark$ & $\checkmark$ & $\checkmark$ & $\checkmark$ & $\checkmark$ & $\checkmark$ \\
\hline Embraer & $\checkmark$ & $\checkmark$ & $\checkmark$ & & $\checkmark$ & $\checkmark$ & $\checkmark$ & & $\checkmark$ & $\checkmark$ & $\checkmark$ & $\checkmark$ & \\
\hline Engie & & & & & & & & & & & $\checkmark$ & $\checkmark$ & $\checkmark$ \\
\hline Even & & & & & $\checkmark$ & $\checkmark$ & $\checkmark$ & $\checkmark$ & $\checkmark$ & $\checkmark$ & $\checkmark$ & & \\
\hline Fibria & & & & & $\checkmark$ & $\checkmark$ & $\checkmark$ & $\checkmark$ & $\checkmark$ & $\checkmark$ & $\checkmark$ & $\checkmark$ & $\checkmark$ \\
\hline Fleury & & & & & & & & & $\checkmark$ & $\checkmark$ & $\checkmark$ & $\checkmark$ & $\checkmark$ \\
\hline Cerdau & & $\checkmark$ & $\checkmark$ & $\checkmark$ & $\checkmark$ & $\checkmark$ & $\checkmark$ & $\checkmark$ & $\checkmark$ & $\checkmark$ & & & \\
\hline Gerdau Metalúrgica & & & $\checkmark$ & $\checkmark$ & $\checkmark$ & $\checkmark$ & $\checkmark$ & $\checkmark$ & $\checkmark$ & $\checkmark$ & & & \\
\hline Col & $\checkmark$ & $\checkmark$ & & & & & & & & & & & \\
\hline Inds Romi & & & & & $\checkmark$ & $\checkmark$ & & & & & & & \\
\hline lochpe-Maxion & $\checkmark$ & $\checkmark$ & $\checkmark$ & & & & & & & & & & \\
\hline Itaú & $\checkmark$ & $\checkmark$ & $\checkmark$ & $\checkmark$ & & & & & & & & & \\
\hline Itaú Unibanco & & & & & $\checkmark$ & $\checkmark$ & & $\checkmark$ & $\checkmark$ & $\checkmark$ & $\checkmark$ & $\checkmark$ & $\checkmark$ \\
\hline Itaúsa & $\checkmark$ & $\checkmark$ & & & $\checkmark$ & $\checkmark$ & $\checkmark$ & $\checkmark$ & $\checkmark$ & $\checkmark$ & $\checkmark$ & $\checkmark$ & $\checkmark$ \\
\hline
\end{tabular}

Fonte: elaborado pelos autores a partir de B3 (2017a, 2017d).

Nota: Em julho de 2016 a empresa Tractebel alterou seu nome para Engie.

O Quadro 7 continua na próxima página.

OS, Organizações e Sustentabilidade, 7(2), p. 62-84, Londrina, PR, jul./dez. 2019

ISSN 2318-9223, http://www.uel.br/revistas/uel/index.php/ros/issue/view/1607/showToc 
Vantagens Competitivas Associadas à Adoção da Responsabilidade Social Corporativa e à Participação no Índice de Sustentabilidade Empresarial

... Continuação do Quadro 7.

QUADRO 7 - COMPOSIÇÃO DAS CARTEIRAS DO ISE ENTRE 2005 E 2018

\begin{tabular}{|c|c|c|c|c|c|c|c|c|c|c|c|c|c|}
\hline \multirow[t]{2}{*}{ Empresa } & \multicolumn{13}{|c|}{ Carteira do ISE } \\
\hline & 2006 & 2007 & 2006 & 2009 & 2006 & 2011 & 2006 & 2013 & 2006 & 2015 & 2006 & 2017 & 2006 \\
\hline JSL & & & & & & & & & $\checkmark$ & $\checkmark$ & $\checkmark$ & $\checkmark$ & $\checkmark$ \\
\hline Klabin & & & $\checkmark$ & $\checkmark$ & $\checkmark$ & $\checkmark$ & $\checkmark$ & $\checkmark$ & $\checkmark$ & $\checkmark$ & $\checkmark$ & $\checkmark$ & $\checkmark$ \\
\hline Light & & $\checkmark$ & & & & & & & & & & & \\
\hline Localiza & & & & & & & & & & $\checkmark$ & $\checkmark$ & $\checkmark$ & $\checkmark$ \\
\hline $\begin{array}{c}\text { Lojas } \\
\text { Americanas }\end{array}$ & & & & & & & & & & $\checkmark$ & $\checkmark$ & $\checkmark$ & $\checkmark$ \\
\hline $\begin{array}{c}\text { Lojas } \\
\text { Renner }\end{array}$ & & & & & & & & & & & & $\checkmark$ & $\checkmark$ \\
\hline MRV & $\checkmark$ & $\checkmark$ & $\checkmark$ & $\checkmark$ & $\checkmark$ & $\checkmark$ & $\checkmark$ & $\checkmark$ & $\checkmark$ & $\checkmark$ & $\checkmark$ & $\checkmark$ & $\checkmark$ \\
\hline Natura & & & & $\checkmark$ & & & & & & & & & \\
\hline Odontoprev & & & & & & & & & $\checkmark$ & & & & \\
\hline Ol & $\checkmark$ & $\checkmark$ & $\checkmark$ & $\checkmark$ & & & & & & & & & \\
\hline Perdigão & & $\checkmark$ & $\checkmark$ & & & & & & & & & & \\
\hline Petrobrás & & & & & $\checkmark$ & $\checkmark$ & $\checkmark$ & & & & & & \\
\hline Redecard & & & $\checkmark$ & $\checkmark$ & $\checkmark$ & $\checkmark$ & $\checkmark$ & $\checkmark$ & $\checkmark$ & $\checkmark$ & & & \\
\hline Sabesp & & & $\checkmark$ & & & & & & & & & & \\
\hline Sadia & & & & & & $\checkmark$ & $\checkmark$ & $\checkmark$ & $\checkmark$ & $\checkmark$ & $\checkmark$ & $\checkmark$ & $\checkmark$ \\
\hline Santander & & & & & $\checkmark$ & $\checkmark$ & $\checkmark$ & $\checkmark$ & $\checkmark$ & $\checkmark$ & $\checkmark$ & $\checkmark$ & \\
\hline SulAmerica & $\checkmark$ & $\checkmark$ & $\checkmark$ & $\checkmark$ & $\checkmark$ & $\checkmark$ & $\checkmark$ & $\checkmark$ & $\checkmark$ & & & & \\
\hline $\begin{array}{c}\text { Suzano } \\
\text { Papel }\end{array}$ & & $\checkmark$ & $\checkmark$ & & & & & & & & & & \\
\hline $\begin{array}{l}\text { Suzano } \\
\text { PETR }\end{array}$ & & $\checkmark$ & & & & & & & & & & & \\
\hline TAM & & & & & & & & $\checkmark$ & $\checkmark$ & $\checkmark$ & $\checkmark$ & $\checkmark$ & $\checkmark$ \\
\hline Telefônica & & & & $\checkmark$ & $\checkmark$ & $\checkmark$ & $\checkmark$ & $\checkmark$ & & & & & \\
\hline Telemar & & & & $\checkmark$ & $\checkmark$ & $\checkmark$ & $\checkmark$ & $\checkmark$ & $\checkmark$ & $\checkmark$ & $\checkmark$ & $\checkmark$ & $\checkmark$ \\
\hline TIM & $\checkmark$ & $\checkmark$ & $\checkmark$ & $\checkmark$ & $\checkmark$ & $\checkmark$ & $\checkmark$ & $\checkmark$ & $\checkmark$ & $\checkmark$ & & & \\
\hline Tractebel & & $\checkmark$ & & & & $\checkmark$ & $\checkmark$ & $\checkmark$ & & & & & \\
\hline Ultrapar & $\checkmark$ & $\checkmark$ & & $\checkmark$ & & & & & & & & & \\
\hline Unibanco & & & & & $\checkmark$ & & & & & & & & \\
\hline Usiminas & & & & & & $\checkmark$ & $\checkmark$ & $\checkmark$ & $\checkmark$ & $\checkmark$ & & & \\
\hline Vale & $\checkmark$ & $\checkmark$ & $\checkmark$ & $\checkmark$ & & & & & & & & & \\
\hline VCP & & & & & $\checkmark$ & $\checkmark$ & & & & & & & \\
\hline Vivo & & & $\checkmark$ & & & & & $\checkmark$ & $\checkmark$ & $\checkmark$ & $\checkmark$ & $\checkmark$ & $\checkmark$ \\
\hline Weg & & & & & & & & & & & & & \\
\hline
\end{tabular}

Fonte: elaborado pelos autores a partir de B3 (2017a, 2017d).

Nota: Em julho de 2016 a empresa Tractebel alterou seu nome para Engie.

De acordo com Wajnberg e Leme (2009), empresas de grande porte e rentabilidade têm cada vez mais aderido ao ISE. IsSo pode ser exemplificado por empresas como Braskem, Cemig, CPFL, Eletropaulo, Natura e Tractebel/Engie, que figuraram em todas as carteiras do ISE. Os dados também revelam uma grande participação de empresas do setor bancário (e.g., Banco do Brasil, Bicbanco, Bradesco, Itaú Unibanco, Santander), energia (e.g., AES Tietê, CPFL, EDP, Eletrobrás, Eletropaulo, Light) e telecomunicação (e.g., Ol, Telefônica, TIM, Vivo).

Dois critérios que não eram contemplados nos questionários anteriores tiveram destaque no ISE 2018, a saber: 98\% afirmaram possuir uma política de riscos; e 95\% possuem processos de gestão de riscos corporativos que consideram aspectos ambientais. 
Um aspecto negativo observado junto a estas empresas diz respeito à diversidade na composição dos conselhos dessas empresas; apenas $50 \%$ das organizações contam com uma ou mais mulheres em seus conselhos. No ano anterior, este número era maior; 56\% das empresas possuíam pelo menos uma mulher no conselho.

Os Objetivos de Desenvolvimento Sustentáveis (ODS), resultantes das ações acordadas no âmbito da agenda voltada para o desenvolvimento sustentável firmada em 2015 pelos países signatários da ONU, que incluem entre outros; ações para acabar com a pobreza, promover a prosperidade e o bemestar para todos, proteger o meio ambiente e enfrentar as mudanças climáticas, foram, segundo 98\% das empresas que fazem parte do ISE 2018, usados em suas práticas de gestão. Dessas, 100\% realizaram análises para identificar a existência de relação direta e significativa entre as práticas empresariais decorrentes de seus compromissos voluntários voltados para os ODS.

Conforme a B3 (2017b, 2017c), estão entre os ODS mais relevantes, segundo as empresas do ISE 2018: Assegurar padrões de produção e de consumo sustentáveis (ODS 12, apontado por 98\%); Construir infraestruturas resilientes, promover a industrialização inclusiva e sustentável e fomentar a inovação (ODS 9, indicado por 91\%); Promover sociedades pacíficas e inclusivas para 0 desenvolvimento sustentável, proporcionar o acesso à justiça para todos e construir instituições eficazes, responsáveis e inclusivas em todos os niveis (ODS 16, apontado por 87\%). De outro lado, entre os ODS menos relevantes na percepção das empresas estão: Assegurar a disponibilidade e a gestão sustentável da água e saneamento para todos (ODS 6, apontado por 52\%); Reduzir a desigualdade dentro dos países e entre eles (ODS 10, apontado por 50\%); Acabar com a pobreza em todas as suas formas e em todos os lugares (ODS1, apontado por 50\%); Acabar com a fome, alcançar a segurança alimentar e melhoria da nutrição e promover a agricultura sustentável (ODS 2, apontado por 33\%); Conservação e uso sustentável dos oceanos, dos mares e dos recursos marinhos para 0 desenvolvimento sustentável (ODS 14, apontado por 9\%).

É crescente a legislação que regulamenta que empresas de diferentes setores produtivos adotem práticas de sustentabilidade social e ambiental. Em decorrência disso, as empresas têm focado na documentação dessas práticas de forma que sejam bem avaliadas qualitativamente como parte do processo de auditoria externa.

Em trabalho amplo, Andrade et al. (2013) desenvolvem um modelo empírico específico para determinar as variáveis relacionadas às empresas listadas no ISE. Os autores verificaram que o tamanho da empresa e o nivel de impacto ambiental, inerente ao setor de atividade, são as variáveis que mais influenciam a adesão.

Recentemente, Austin e Gaither (2017) e Wang e Sarkis (2017) buscaram analisar o perfil socioeconômico das empresas listadas no Dow Jones Sustainability Index. Em termos de índices de endividamento e rentabilidade, os autores encontraram resultados semelhantes aos das empresas brasileiras. Por outro lado, no exterior, destacam-se aquelas com grande valor de mercado e foco na manufatura, que também se submetem às legislações específicas ao setor de atuação.

\section{RESPONSABILIDADE SOCIAL CORPORATIVA E DESEMPENHO FINANCEIRO: RELAÇÃO POSITIVA, NEUTRA OU NEGATIVA?}

O conceito de investimento unicamente atrelado ao potencial de lucro das empresas começa a dar espaço ao investimento em condutas que valorizem e considerem ações sociais e ambientais. Este investimento relacionado às preocupações sustentáveis e ambientais tem sido incorporado pelas empresas segundo a rubrica dos "investimentos sustentáveis" (IS), ou seja, aqueles praticados por empresas consideradas sustentáveis (Jeucken, 2001).

O número crescente de bolsas de valores signatárias da Iniciativa Sustentável das Bolsas de Valores revela que os IS têm se tornado um importante valor aceito e compartilhado globalmente (Sartore, 
2016). Por outro lado, segundo Wajnberg e Leme (2009), são poucas as empresas que associam suas práticas de sustentabilidade ao desempenho financeiro corporativo na divulgação pública de suas informações.

Diversos estudos internacionais que tratam de temas relacionados aos IS, ao abordarem a sustentabilidade considerando o mercado de capitais e as bolsas de valores, defendem uma relação positiva entre rentabilidade financeira e adoção de práticas sustentáveis (Waddock \& Graves, 1997; Igalens \& Gond 2005; Jones et al., 2007; Sakuma \& Louche, 2008). Na literatura nacional, tal relação também tem sido identificada (Teixeira et al., 2011; Comes \& Tortato, 2011; Andrade et al., 2013).

Artiach et al. (2010) afirmam que as empresas que aderem à RSC têm niveis mais elevados de crescimento e um maior retorno sobre o patrimônio do que as empresas convencionais. Waddock e Graves (1997) e Clarkson et al. (2006) concordam que as empresas que investem em RSC possuem capital e recursos suficientes para que as mesmas possam arcar com os custos relativos à RSC sem sofrer prejuízo financeiro.

Complementarmente, McGuire et al. (1988) e Barnett (2005) partilham a ideia de que as vantagens dos investimentos em RSC são superiores aos seus custos, além de proporcionar melhor relacionamento com instituições financeiras, governos e investidores.

Em contrapartida, há estudos que questionam tal relação. Na visão de alguns desses autores, os estudos realizados até então não são suficientes para afirmar tal relação positiva entre RSC e desempenho financeiro. Tal argumento é amparado pela complexidade em se mapear e controlar os fatores externos a esta relação (Ullmann, 1985). Apesar de tal questionamento ter primeiramente ocorrido há mais de 40 anos (Alexander \& Buchholz, 1978), ele se mantém atual (ver Kim et al., 2018).

Aupperle et al. (1985) afirmam não haver nenhuma relação significativa entre RSC e desempenho financeiro. Na mesma linha, Gomes e Tortato (2011) compararam o retorno do ISE em relação a outros índices de ações da Bovespa e concluíram que, apesar do ISE possuir uma carteira teórica diferenciada, propiciando um ambiente de investimento compatível com as demandas de desenvolvimento sustentável da sociedade contemporânea, seu retorno não é significativamente diferente em relação ao obtido pelos índices de ações convencionais.

Outro estudo semelhante, realizado por Machado et al. (2009), conclui que os investimentos socialmente responsáveis apresentam o mesmo retorno de investimentos que não adotam postura idêntica, mas que o retorno médio dos índices é semelhante, uma vez que um número relevante de empresas compõe simultaneamente mais de um índice.

De maneira geral, tais autores defendem que a RSC acarreta em custos adicionais relacionados às condições de trabalho, desenvolvimento comunitário, incorporação de práticas ambientais e, principalmente, a renúncia de projetos de investimentos que não são consideradas socialmente responsáveis, sendo os acionistas os responsáveis por arcar com esse custo de oportunidade.

Partindo de uma visão mais equilibrada, Becchetti et al. (2008) defendem que a RSC implica, por um lado em custos mais altos relacionados ao trabalho e à produção; por outro, ela pode aumentar o envolvimento, a motivação e a identificação dos trabalhadores com objetivos da empresa, acarretando em efeitos positivos sobre a produtividade.

Andrade et al. (2013) desenvolveram um modelo estatístico para avaliar as variações de valor de mercado das empresas listadas e não listadas no ISE. De acordo com os autores, em 2009, 2010 e 2011, os valores de mercado das empresas listadas apresentaram uma média menor que as empresas não listadas. Por outro lado, em 2008, ano da crise financeira mundial, as quedas das ações das empresas não listadas foram percentualmente maiores em relação àquelas listadas no ISE. Além disso, de um total de 13 casos de empresas que decidiram pela saída, 11 apresentaram variações negativas em suas ações.

OS, Organizações e Sustentabilidade, 7(2), p. 62-84, Londrina, PR, jul./dez. 2019. 
Embora os fatores que levam à saída das empresas do ISE não seja o foco desta pesquisa, diversos autores destacam a dificuldade que as empresas encontram para se adequar às normas e exigências da manutenção das empresas no índice e o descontentamento de parte dos acionistas no que diz respeito aos custos relacionados às práticas de RSC.

\section{A RSC E A IMAGEM DA EMPRESA FRENTE AOS STAKEHOLDERS}

Sartore (2016) ressalta que as vantagens obtidas pelas empresas com o investimento em RSC vão além dos ganhos diretamente associados à valorização de suas ações. A autora argumenta que 0 entendimento acerca da ascensão das ideias ligadas à RSC pode ocasionar novos enquadramentos morais e culturais capazes de fortalecer diferenciais frente a um mercado de consumo mais consciente e sustentável, que já existe e vem ganhando cada vez mais espaço.

Figueiredo et al. (2009) realizaram uma pesquisa de mercado junto aos alunos da PUC-SP para avaliar a percepção dos clientes em relação às empresas listadas no índice. A amostra foi composta por 176 jovens consumidores e futuros gestores de marketing. Os autores encontraram que $74 \%$ dos entrevistados não tinham conhecimento da existência do ISE ou das empresas que o compõem, incluindo funcionários das próprias empresas entre os entrevistados. Depois de informados sobre o funcionamento e o conceito do ISE, 94\% dos entrevistados mostraram-se favoráveis à sua adoção. Os autores ainda identificaram que $95 \%$ considerariam um diferencial a participação da empresa no ISE e que $71 \%$ estaria disposto a pagar 30\% mais caro pelos produtos dessas empresas.

Navarro et al. (2016) destacam as possibilidades de inovação que podem surgir a partir das ações de RSC. Os autores apontam que as empresas que valorizam a inovação no seu modelo de negócio possuem um canal de comunicação mais amplo e consolidado com seus consumidores. Dessa forma, as ações sustentáveis ganham maior visibilidade e são mais valorizadas pelos stakeholders, tendo como consequência um maior ganho de mercado.

Em linhas gerais, apesar de haver estudos recentes que ainda argumentem não ser possivel fazer afirmações sobre a relação entre RSC e desempenho organizacional, autores como Milani Filho (2008) e Silva et al. (2009) destacam que caminhamos cada vez mais para uma visão mais otimista sobre a relação entre o ISE e o desempenho global frente ao mercado. Para estes autores, a tendência é que os acionistas aumentem sua confiança na adoção de tais práticas vislumbrando resultados positivos em longo prazo.

\section{CONSIDERAÇÕES FINAIS}

Este trabalho buscou explorar a relação entre as práticas de RSC e o desempenho das empresas, tanto financeiro, como também em termos de sua imagem frente aos stakeholders. Tais aspectos foram analisados por meio da literatura nacional e internacional, além de relatórios publicados pelas empresas listadas no ISE e de pesquisa na imprensa de negócios. O ISE mostrou-se favorável para tal análise, principalmente em função da facilidade de acesso aos dados. Tal constatação pode ser evidenciada pelo número de trabalhos que utilizam o ISE como parâmetro de comparação (e.g., Silva et al., 2009; Machado et al., 2009; Nunes et al., 2010; Costa \& Boente, 2011; Andrade et al., 2013; Sartore, 2016).

Embora o conceito de RSC não seja novidade (Bowen, 1953), tampouco a discussão sobre sua relação com o desempenho das empresas que aderem às suas práticas - como mostram os trabalhos de Alexander et al. (1978), Ullman (1985) e Aupperle et al. (1985) -, há um amplo debate sobre o tema, assim como um constante aprimoramento dos métodos aplicados e um refinamento das análises.

Com base nos relatórios divulgados pela B3 e pelas próprias empresas listadas nas carteiras do ISE foi possivel observar a tendência crescente de empresas de grande porte e de grande rentabilidade

OS, Organizações e Sustentabilidade, 7(2), p. 62-84, Londrina, PR, jul./dez. 2019

ISSN 2318-9223, http://www.uel.br/revistas/uel/index.php/ros/issue/view/1607/showToc 
aderirem a tais preceitos (ver Quadro 7). Destacam-se as empresas dos setores bancário, energético e de telecomunicações.

Em relação às características da RSC abordadas pelo ISE, destacam-se os pontos presentes no questionário respondido pelas empresas referentes às questões relacionadas à diversidade e ao bem-estar dos trabalhadores e da comunidade em que a instituição está inserida.

Em relação às vantagens obtidas pelas empresas que aderem às práticas da RSC, é possível afirmar que não há consenso. Alguns autores acreditam na maior valorização das ações daquelas empresas listadas no ISE (e.g., Barnett, 2005; Clarkson et al., 2006; Artiach et al., 2010; Vasconcelos \& Hourneaux Júnior, 2017); outros afirmam não ser possível fazer tal afirmação (e.g., Machado et al., 2009; Comes \& Tortato, 2011; Kim et al., 2018); e ainda há outros autores que defendem que os custos da RSC ainda são muito alto para as empresas (e.g., Alexander \& Buchholz, 1978) e os que enxergam simultaneamente vantagens e desvantagens na adoção dessas práticas (Becchetti et al., 2008).

O debate sobre o tema está longe de ser concluído. Contudo, de maneira geral, é possível perceber uma tendência à valorização dessas práticas sociais tanto pelos consumidores quanto pelos acionistas (Milani Filho, 2008; Silva et al., 2009), principalmente por acreditarem nas oportunidades que as mesmas possam trazer no futuro (Sartore, 2016).

A RSC passa a ser vista pelas empresas como uma alternativa estratégica. Essa questão ganha ainda mais importância em tempos de crise financeira e de acirramento da disputa por mercado (Andrade et al., 2013), e diante de um cenário onde os stakeholders, cada vez mais, prezam e valorizam tais práticas. Assim, espera-se que este estudo contribua tanto para a teoria quanto para a prática da RSC ao explorar diferentes visões sobre sua relação com o desempenho financeiro e a imagem das empresas, integrando dados provenientes da literatura, imprensa de negócios e das próprias empresas.

\section{REFERÊNCIAS}

Aguinis, H., \& Glavas, A. (2012). What we know and don't know about corporate social responsibility: A review and research agenda. Journal of Management, 38, 932-968.

Alexander, G. \& Buchholz, R. (1978). Corporate Social Responsibility and Stock Market Performance. Academy of Management Journal, 21(3), 479-486.

Andrade, L. P., Bressan, A. A., Iquiapaza, R. A., \& de Melo Moreira, B. C. (2013). Determinantes de adesão ao Índice de Sustentabilidade Empresarial da BM\&FBOVESPA e sua relação com o valor da empresa. Revista Brasileira de Finanças, 11(2), 181-213.

Antoniolli, G. O. \& Dias, S. L. F. G. (2013). Uma discussão em torno de Responsabilidades, Comunicação Ambiental e Greenwashing: o caso Petrobras. Organizações \& Sustentabilidade, 3(1), 3-46.

Artiach, T., Lee, D., Darren, N. \& Walker, J. (2010). The Determinants of Corporate Sustainability Performance. Accounting \& Finance, 50(1)1, 31-51.

Aupperle, K., Carroll, A. \& Hatfield, J. (1985). An Empirical Examination of the Relationship Between Corporate Social Responsibility and Profitability. Academy of Management Journal, 28(2), 446-463.

Austin, L., \& Gaither, B. M. (2017). Perceived motivations for corporate social responsibility initiatives in socially stigmatized industries. Public Relations Review, 43(4), 840-849.

Barnett, M. L. (2007). Stakeholder influence capacity and the variability of financial returns to corporate social responsibility. Academy of Management Review, 32(3), 794-816.

OS, Organizações e Sustentabilidade, 7(2), p. 62-84, Londrina, PR, jul./dez. 2019.

ISSN 2318-9223, http://www.uel.br/revistas/uel/index.php/ros/issue/view/1607/showToc 
Bassetto, L. I. (2010). A incorporação da responsabilidade social e sustentabilidade: um estudo baseado no relatório de gestão 2005 da companhia paranaense de energia. Cestão \& Produção, 17(3), 639-651.

Becchetti, L., Di Giacomo, S., \& Pinnacchio, D. (2008). Corporate social responsibility and corporate performance: evidence from a panel of US listed companies. Applied Economics, 40(5), 541-567.

Benites, L. L. L. \& Polo, E. F. (2013). A sustentabilidade como ferramenta estratégia empresarial: governança corporativa e aplicação do triple bottom line na massa. Revista de Administração da UFSM, 6, 195-210.

B3. (2017a). B3 divulga a 13a carteira do ISE - Indice de Sustentabilidade Empresarial. 23 nov. 2017. Recuperado de: <https://isebvmf.com.br/b3-divulga-a-13-carteira-do-ise-indice-desustentabilidade-empresarial/?locale=pt-br>.

B3. (2017b). B3 divulga resultados do "Relate ou Explique para os Objetivos de Desenvolvimento Sustentável (ODS)". 22 set. 2017. Recuperado de: <http://www.b3.com.br/pt_br/noticias/relate-ouexplique.htm>.

B3. (2017c). Banco de dados da B3 - Relate ou Explique para os Objetivos de Desenvolvimento Sustentável (ODS). Recuperado de: <http://www.b3.com.br/pt_br/institucional/sustentabilidade/nas-empresas/relate-ouexplique/>.

B3. (2017d). Carteiras e questionários. 23 nov. 2017. Recuperado de: < http://isebvmf.com.br/carteiras-e-questionarios-3?locale=pt-br>.

BM\&F Bovespa. (2016a). Novo Valor - Sustentabilidade nas empresas como começar, quem envolver e o que priorizar. Brasil. Recuperado de: <http://www.bmfbovespa.com.br/pt_br/institucional/sustentabilidade/nasempresas/publicacoes-e-encontros/>.

BM\&F Bovespa. (2016b). BM\&FBOVESPA divulga a $12^{a}$ carteira do ISE - Indice de Sustentabilidade Empresarial. $24 \quad$ nov. 2016.2 Recuperado de: <http://www.bmfbovespa.com.br/pt_br/institucional/imprensa/ultimos-releases/bm-fbovespadivulga-a-12-carteira-do-ise-indice-de-sustentabilidade-empresarial.htm>.

Borger, F. G. (2001). Responsabilidade Social: Efeitos da atuação social na dinâmica empresarial. Tese de Doutorado em Administração, Faculdade de Economia, Administração e Contabilidade, Universidade de São Paulo, São Paulo, Brasil.

Bowen, H. R. (1953). Social responsibilities of the businessman. University of lowa Press.

Caldelli, A. \& Pamigiani, L. (2004). Management Information System A Tool for Corporate Sustainbility. Journal of Business Ethics, 55(2), 159-171.

Broome M. E. (1993). Integrative literature reviews for the development of concepts. In Rodgers B.L., \& K.A. Knafl (Eds.), Concept Development in Nursing (pp. 231-250). Philadelphia: W.B. Saunders Co.

Brunoro, C. M., Bolis, I., Pereira, L. F., \& Sznelwar, L. I. (2013). Sustentabilidade Corporativa, Responsabilidade Social Corporativa e Trabalho: uma abordagem teórica. In Silveira, M. A., Sznelwar, L. I., Kikuchi, L. S., \& Maeno, M. (Orgs.), Inovação para desenvolvimento de organizações sustentáveis (pp. 79-99). Campinas: CTI.

Clarkson, P. M., Li, Y., Richardson, G. D., \& Vasvari, F. P. (2011). Does it really pay to be green? Determinants and consequences of proactive environmental strategies. Journal of Accounting and Public Policy, 30(2), 122-144.

OS, Organizações e Sustentabilidade, 7(2), p. 62-84, Londrina, PR, jul./dez. 2019 
Coral, E. (2002). Modelo de planejamento estratégico para sustentabilidade empresarial. Tese de Doutorado em Engenharia de Produção, Departamento de Engenharia de Produção, Universidade Federal de Santa Catarina, Florianópolis, Brasil.

Costa, S. F., \& Boente, D. R. (2011). Avaliação da eficiência econômico-financeira das empresas integrantes do indice de sustentabilidade empresarial por meio da análise envoltória de dados. Revista Ambiente Contábil, 3(2), 75-99.

Esteves, M. L., Silva, S. S. \& Aligleri, L. M. (2007). Gestão estratégica da responsabilidade social: 0 caso das empresas do setor de atacado e comércio exterior na Região Sul do País. Revista FAE, 10(1), $19-26$.

Ferreira, R. N. (2004). Responsabilidade social, governança corporativa e valor das empresas. Revista de Administração da UFLA, 6(1), 132-141.

Figueiredo, G. B., Abreu, R. L. \& Casas, A. L. L. (2009). Reflexos do Índice de Sustentabilidade Empresarial (ISE) na Imagem das Empresas: uma Análise do Consumidor Consciente e do Marketing Ambiental. Pensamento \& Realidade, 24(1), 107-128.

Garriga, E., \& Melé, D. (2004). Corporate social responsibility theories: Mapping the territory. Journal of Business Ethics, 53(1-2), 51-71.

Gomes, A. D. N., Souza, A. L., Coelho, F. M. G., \& Silva, M. L. (2005). Sustentabilidade de empresas de base florestal: o papel dos projetos sociais na inclusão das comunidades locais. Revista Árvore, 30(6), 951-960.

Comes, F. P. \& Tortato, U. U. (2011). Adoção de Práticas de Sustentabilidade como Vantagem Competitiva: Evidências Empíricas. Revista Pensamento Contemporâneo em Administração, 5(2), 33-49.

Hiss, S. (2013). The politics of the financialization of sustainability. Competition \& Change, 17(3), 234247.

Hopia, H., Latvala, E. \& Liimatainen, L. (2016) Reviewing the methodology of an integrative review. Scandinavian Journal of Caring Sciences, 30, 662-669

Igalens, J. \& Cond, J. P. (2005). Measuring Corporate Social Performance in France: a critical and empirical analysis of ARESE data. Journal of Business Ethics, 56(2), 131-148.

Jeucken, M. (2001). Sustainable Finance and Banking: the financial sector and the future of the planet. Londres: Routhledge. $336 \mathrm{p}$.

Jones, S., Laan, S.V., Frost, G. \& Loftus, J. (2008). The investment performance of Socially Responsible Investment Funds in Australia. Journal of Business Ethics, 80(2), 181-203.

Kim, K. H., Kim, M., \& Qian, C. (2018). Effects of corporate social responsibility on corporate financial performance: A competitive-action perspective. Journal of Management, 44(3), 1097-1118.

McGuire, J. Sundgren, A. \& Schneeweis, T. (1988). Corporate Social Responsibility and Firm Financial Performance. Academy of Management Journal, 31(4), 854-872.

Machado, M. R., Verdas, M. A. \& Corrar, L. J. (2009). Desempenho do Índice de Sustentabilidade Empresarial (ISE) da Bolsa de Valores de São Paulo. Revista Universo Contábil, 5(2), 24-38.

Machado Filho, C. A. P., Claudio, A. \& Zylbersztajn, D. (2004). A Empresa Socialmente Responsável: O Debate e as Implicações. Revista de Administração da USP, 39(3), 242-254.

OS, Organizações e Sustentabilidade, 7(2), p. 62-84, Londrina, PR, jul./dez. 2019. 
Matten, D., \& Moon, J. (2008). "Implicit" and "explicit" CSR: A conceptual framework for a comparative understanding of corporate social responsibility. Academy of Management Review, $33(2), 404-424$

May, P., Lustosa, M. C. \& Vinha, V. (2003). Economia do meio ambiente: teoria e prática. Rio de Janeiro: Campus, $318 \mathrm{p}$.

McGuire, J. B., Sundgren, A., \& Schneeweis, T. (1988). Corporate social responsibility and firm financial performance. Academy of Management Journal, 31(4), 854-872.

Milani Filho, M. A. F. (2008). Responsabilidade social e investimento social privado: entre o discurso e a evidenciação. Revista Contabilidade \& Finanças, 19(47), 89-101.

Navarro, J. G. C., Reverte, C., Melero, E. G. \& Wensley, A. K. P. (2016). Linking social and economic responsibilities with financial performance: The role of innovation. European Management Journal, 34(5), 530-539.

Nunes, J. G., Teixeira, A. J. C. Nossa, V. \& Galdi, F. C. (2010). Análise das variáveis que influenciam a adesão das empresas ao índice BMধF Bovespa de Sustentabilidade Empresarial. Revista de Administração e Contabilidade da Unisinos, 7(4), 328-340.

Nidumolu, R., Prahalad, C. K., \& Rangaswami, M. R. (2009). Why sustainability is now the key driver of innovation. Harvard Business Review, 87(9), 56-64.

Quazi, A. M., \& O'Brien, D. (2000). An empirical test of a cross-national model of corporate social responsibility. Journal of Business Ethics, 25(1), 33-51.

Pacheco, L. M., Krüger, C., Lourenção, M. T. A. \& Caldana, A. C. F. (2016). A Evolução da Responsabilidade Corporativa em Empresa do Setor Elétrico Brasileiro: um Estudo de Caso. Organizações \& Sustentabilidade, 4(1), 84-115.

Rezende, I. A. C., Nunes, J.G. \& Portela, S.S. (2008). Um Estudo sobre o desempenho financeiro do Índice Bovespa de Sustentabilidade Empresarial. Revista de Educação e Pesquisa em Contabilidade, 2(1), 71-93.

Russell, C. L. (2005). An overview of the integrative research review. Progress in transplantation, 15(1), 8-13.

Sachs, I. (1993). Estratégias de transição para o século XXI: desenvolvimento e meio ambiente. São Paulo: Studio Nobel.

Sakuma, K. \& Louche, C. (2008). Socially Responsible Investment in Japan: its mechanism and drivers. Journal of Business Ethics, 82(2), 425-448.

Sartore, M. S. (2016). A difusão do Investimento Sustentável: reflexões a partir da Iniciativa para a Bolsa de Valores Sustentável. Política \& Sociedade, 15(33), 193-217.

Savitz, A.W. \& Weber, K. (2007). A empresa sustentável: o verdadeiro sucesso é o lucro com responsabilidade social e ambiental. Rio de Janeiro: Elsevier.

Silva, J. O., Wienhage, P., Rocha, I. \& Rausch, R. B. (2009). Gestão Ambiental: uma análise da Evidenciação das Empresas que compõem o Índice de Sustentabilidade Empresarial (ISE). Revista de Gestão Social e Ambiental, 3(3), 56-57.

Schaltegger, S., Burritt, R. \& Petersen, H. (2003). An introduction to corporate environmental management: striving for sustainability. Sheffield: Greenleaf.

Souza, M.T., Silva, M.D.S. \& Carvalho, R. (2010). Revisão integrativa: o que é e como fazer? Revista Einstein, 8(1), 102-106.

OS, Organizações e Sustentabilidade, 7(2), p. 62-84, Londrina, PR, jul./dez. 2019. 
Teixeira, E. A., Funchal, B. \& Nossa, V. (2011). O índice de sustentabilidade empresarial (ISE) e os impactos no endividamento e na percepção de risco. Revista Contabilidade \& Finanças, 22(55), 2944.

Ullmann, A. (1985). Data in Search of a Theory: A Critical Examination of the Relationships Among Social Performance, Social Disclosure, and Economic Performance of U.S. Firms. Academy of Management Review, 10(3), 540-557.

Vasconcelos, I. B. \& Hourneaux Júnior, F. (2017). As Práticas Sustentáveis nas Organizações e a Geração de Valor para o Investidor Institucional. Organizações \& Sustentabilidade, 5(2), 115-148.

Waddock, S. \& Graves, S. (1997). The Corporate Social Performance -Financial Performance Link. Strategic Management Journal, 18(4), 303-319.

Wajnberg, D. \& Leme, C. (2009). Exame da divulgação do relacionamento entre iniciativas socioambientais e desempenho financeiro corporativo nos bancos brasileiros. Revista de Gestão Social e Ambiental, 3(1), 53-69.

Wang, Z. \& Sarkis, J. (2017). Corporate Social Responsibility Governance, Outcomes, and Financial Performance. Journal of Cleaner Production, 162(20), 1607-1616.

Whittemore, R., \& Knafl, K. (2005). The integrative review: update methodology. Journal of Advanced Nursing, 52(5), 546-53. 